\title{
Incidence of complications after cardiac surgery
}

\begin{abstract}
Introduction: Cardiovascular diseases are one of the leading causes of death in the world their treatment is based on surgery, medication and installation of healthy habits. Among the treatments, the surgical one is the most complex and it has been increasing exponentially over the years, although its relevance has a significant mortality rate and an incidence of various complications. Objective: Describe the incidence of complications in patients undergoing cardiac surgery. Methodology: This is an observational study, with characteristics of an analytical study without any intervention. We followed the patients from the first postoperative day until hospital discharge through an assessment in the medical records through a questionnaire prepared by the project authors containing identification, surgery data and possible complications of cardiovascular, neurological, pulmonary, digestive, infectious renal origin, hydroelectrolytic and hematological. Results: Fifty two patients participated in the study, 30 (58\%) males, with a mean age of $54 \pm 10$ years. The most common complications were atelectasis $22(42 \%)$, arrhythmia $6(12 \%)$, stroke $2(4 \%)$, and pulmonary infection $5(10 \%)$. Conclusion: Thus, the most frequent complications in the immediate postoperative period of patients undergoing cardiac surgery are pulmonary, cardiac and neurological.
\end{abstract}

Keywords: postoperative complications, surgical procedures, cardiac surgery
Volume 5 Issue I - 2020

\author{
Alissandra Almeida Matos,' Daniela Bispo \\ Silva,' Maiane Lima De Jesus, ' André \\ Raimundo Guimarães, ${ }^{2}$ André Luiz Lisboa \\ Cordeiro ${ }^{3}$ \\ 'Faculdade Nobre, Feira de Santana, Brazil \\ ${ }^{2}$ Instituto Nobre de Cardiologia, Feira de Santana, Brazil \\ ${ }^{3}$ Escola Bahiana de Medicina e Saúde Pública, Brazil
}

Correspondence: André Luiz Lisboa Cordeiro, Department of Physiotherapy, Escola Bahiana de Medicina e Saúde Pública, Brazil,Tel +55 75998226086 ,

Email andrelisboacordeir@gmail.com

Received: January 04, 2020 | Published: January 17, 2020

\section{Introduction}

The leading cause of death worldwide is cardiovascular disease, according to the World Health Organization (WHO), predominating in elderly patients. ${ }^{1}$ The treatment for these diseases is through surgery, the vast majority being performed by the Unified Health System, medications, changes in eating habits and physical activity. Surgery is a safe procedure for the treatment of coronary artery disease (CAD), as it can be performed in elderly, diabetic patients with low left ventricular ejection fraction. This procedure controls persistent ischemia and the evolution of acute myocardial infarction, relieving symptoms and preventing ischemic complications. ${ }^{2,3}$

In Brazil, the prevalence of cardiac surgeries has been increasing every year, the most common being myocardial revascularization and valve replacement, and several studies have shown that both are the best way to treat coronary insufficiency. In 2015 there were 91,738 deaths, an average of 7,645 deaths per month and in 2016 there were 45,900 deaths an average of 7,650 per month, an increase of $0.7 \%{ }^{4,5}$

Associated diseases and risk factors are the major causes of postoperative complications after cardiac surgery, such as age, gender, cardiopulmonary bypass time, diabetes, obesity, heart or kidney failure, acute myocardial infarction, balloon use. surgery, preoperative medication and reoperations. ${ }^{6}$

There are several postoperative complications of cardiac surgery and the main ones are pulmonary, neurological and cardiovascular. Cardiovascular complications are more prevalent in cases of acute myocardial infarction and congestive heart failure. On the other hand, neurological complication is stroke which may appear in the first 24 hours after surgery. Complications of pulmonary origin are atelectasis, pneumonia, acute respiratory failure, acute respiratory distress syndrome (ARDS) and pleural effusion..$^{7-9}$
Therefore, the aim of this study is to describe the incidence of complications in patients undergoing cardiac surgery.

\section{Methodology}

\section{Study design}

This is an observational study, with characteristics of an analytical study without any intervention. The field study was conducted at the Intensive Care Unit and Inpatient Unit of a cardiology reference center in the city of Feira de Santana - Bahia. The study was approved by the Research Ethics Committee of the Noble Faculty, Opinion No. 2,382,707, and all participants who agreed and met the inclusion criteria signed the Informed Consent Form before the study began.

\section{Eligibility criteria}

Inclusion criteria were patients of both sexes, over 18 years old and submitted to cardiac surgery (valve replacement, mitral valve myocardial revascularization, correction of interarterial and combined communication) via median sternotomy and cardiopulmonary bypass. Exclusion criteria were patients who did not have sufficient data in the medical records or refused to sign the informed consent form.

\section{Study protocol}

Preoperatively, it was explained in relation to the research objective, where the patients accepted and signed the Informed Consent Form. We followed the first postoperative day until hospital discharge through an evaluation of the medical records through a questionnaire prepared by the project authors containing identification, surgery data (duration, $\mathrm{CPB}$ time, MV and extubation time), and possible complications. that may appear after surgery, being of cardiac origin (acute myocardial infarction, congestive heart failure and arrhythmia), pulmonary (atelectasis, pneumonia, 
pleural effusion, acute respiratory failure, acute respiratory distress syndrome, hypoxemia, associated pneumonia). MV, acute pulmonary edema, pneumothorax, bronchospasm and phrenic nerve palsy), neurological (stroke and stroke), renal (acute renal failure, low renal perfusion, increased serum creatinine and decreased urinary output), digestive tract (mesenteric ischemia and digestive haemorrhage), infectious monarchs, urinary tract infections, mediastinitis infections, endocarditis infections, sternal incisions, saphenous incisions, radial and surgical site incisions), hematologic (thrombotic events and bleeding), hydroelectrolytic (changes in serum sodium, potassium, magnesium, calcium, chlorine and phosphate) and the antecedents (obesity, smoking, diabetes mellitus, hypertension and PLL). The occurrence of the complication was verified through the medical records and the medical team.

\section{Statistical analysis}

For data analysis, the Statistical Package for Social Sciences (SPSS) version 20.0 was used. Data were expressed as mean and standard deviation or absolute value and percentage.

\section{Results}

During the research period, 60 patients were hospitalized for myocardial revascularization surgery and valve replacement was excluded 8 , all due to lack of information in the medical records. Therefore, 52 patients were evaluated, $30(58 \%)$ male and with a mean age of $54 \pm 10$ years. Other clinical data are expressed in Table 1.

Table I Clinical and surgical data of the studied patients

\begin{tabular}{ll}
\hline Variable & $\mathbf{n}=\mathbf{5 2}$ \\
\hline Gender & $\mathrm{n}(\%)$ \\
Male & $30(58 \%)$ \\
Feminine & $22(32 \%)$ \\
Variable & Mean \\
Age (years) & $54 \pm 10$ \\
Body mass index (kg/m2) & $25 \pm 3$ \\
Variable & $\mathbf{n}=\mathbf{5 2}$ \\
Comorbidities & $\mathbf{n}(\%)$ \\
Systemic Arterial Hypertension & $28(54 \%)$ \\
Diabetes Mellitus & $19(37 \%)$ \\
Dyslipidemia & $15(29 \%)$ \\
Sedentary lifestyle & $20(38 \%)$ \\
Type of surgery & \\
Coronary Artery Bypass Grafting & $35(67 \%)$ \\
Valve Replacement & $17(33 \%)$ \\
Variable & $\mathbf{M e a n}$ \\
CPB time (minutes) & $89 \pm 5$ \\
MV time (hours) & $6 \pm 2$ \\
Number of grafts & $2 \pm 1$ \\
Number of Drains & $2 \pm 1$ \\
Surgery time (minutes) & $287 \pm 56$ \\
\hline
\end{tabular}

$\mathrm{CPB}$, cardiopulmonary bypass; $\mathrm{MV}$, mechanical ventilation
Table 2 shows the data on the pulmonary complications found. Of the nine complications, the most prevalent was atelectasis $22(42 \%)$ and lower bronchospasm 2 (4\%)

Table 2 Pulmonary complications found in the study population

\begin{tabular}{ll}
\hline Variable & $\mathbf{n}=\mathbf{5 2}$ \\
\hline Pulmonary Complications & $\mathrm{n}(\%)$ \\
Accute respiratory insufficiency & $\mathrm{II}(2 \mathrm{I} \%)$ \\
Pleural effusion & $16(3 \mathrm{I} \%)$ \\
Hypoxemia & $9(17 \%)$ \\
MV-Associated Pneumonia & $5(10 \%)$ \\
Acute Pulmonary Edema & $3(6 \%)$ \\
Pneumothorax & $5(10 \%)$ \\
Atelectasis & $22(42 \%)$ \\
Bronchospasm & $2(4 \%)$ \\
Phrenic nerve palsy & 0 \\
\hline
\end{tabular}

MV, mechanical ventilation

Table 3 shows the percentage of cardiac complications found, the most common being arrhythmia $6(12 \%)$.

Table 3 Cardiac complications found in the study population

\begin{tabular}{ll}
\hline Variable & $\mathbf{n = 5 2}$ \\
\hline Heart Complications & $\mathrm{n}(\%)$ \\
Perioperative AMI & $3(6 \%)$ \\
Arrhythmia & $6(12 \%)$ \\
\hline
\end{tabular}

AMI, acute myocardial infarction

Table 4 shows the values found for neurological complications, with the highest incidence being stroke 2 (4\%).

Table 4 Neurological complications found in the study population

\begin{tabular}{ll}
\hline Variable & $\mathbf{n}=\mathbf{5 2}$ \\
\hline Neurological Complications & $\mathrm{n}(\%)$ \\
Stroke & $2(4 \%)$
\end{tabular}

Data from infectious complications were the highest incidence of pulmonary origin $5(10 \%)$ and the lowest incidence of mediastinitis 1 (2\%) . The values are expressed in Table 5.

Table 5 Infectious complications found in the study population

\begin{tabular}{ll}
\hline Variable & $\mathbf{n}=\mathbf{5 2}$ \\
\hline Infectious Complications & $\mathrm{n}(\%)$ \\
Pulmonary & $5(10 \%)$ \\
Surgical site & $3(6 \%)$ \\
Urinary & $2(4 \%)$ \\
Endocarditis & $2(4 \%)$ \\
Mediastinitis & $\mathrm{I}(2 \%)$ \\
\hline
\end{tabular}

\section{Discussion}

With this study, it was observed that patients undergoing cardiac 
surgery are prone to a series of pulmonary, cardiac, neurological and infectious complications. The most frequent incidents were: Atelectasis (41\%), Arrhythmia (12\%), Stroke (4\%) and Lung infections (10\%).

Studies have shown that the incidence of male patients with complications after cardiac surgery is higher than that of female patients. Also in this study, the age range found indicates an average age greater than 54 years. ${ }^{910}$ In this sense, we see a result similar to that found in the research, which suggests that this potential audience requires greater care.

Several studies associate comorbidities with postoperative complications and point out that the most common past diseases are hypertension, diabetes mellitus and dyslipidemias., $3,9,10$

In addition to comorbidities, postoperative complications are in many cases also associated with BMI. A cross-sectional and a longitudinal study ${ }^{10,12}$ found that the highest percentage of patients with complications after cardiac surgery are concentrated in the level of overweight and obesity. The authors pointed out that the number of patients with BMI alteration can vary between $29 \%$ and $45 \%$.

A cross-sectional study conducted in Minas Gerais ${ }^{9}$ with 204 patients found that $58 \%$ of the patients had complications and of these the highest rate was pulmonary $(31.02 \%)$, followed by cardiac $(15.78 \%)$ and neurological (13.9\%) complications. . Of the infectious complications, the most prevalent site of infection was the pulmonary $(9.89 \%)$. The significant number of pulmonary complications may be justified by the need for tracheal intubation for up to 48 hours after surgery, which is a mandatory item in this type of procedure. ${ }^{5}$

Calles et al. ${ }^{11}$ conducted a study with 168 patients, in this sample $27.5 \%$ had pulmonary complications, were identified: pleural effusion $(17.9 \%)$, atelectasis $(5.4 \%)$, pneumothorax $(1.2 \%)$, pulmonary edema $(1.2 \%)$, acute respiratory failure $(1.2 \%)$ and bronchopneumonia $(0.6 \%)$. These findings reinforce the idea that pulmonary complications are the most recurrent and are justified, as it is known that cardiac surgery independent of the technique leads to decreased pulmonary function. ${ }^{12}$

In addition to pulmonary complications, neurological complications are widely studied Carrascal et al. ${ }^{12}$ collected data from 2,528 patients who underwent cardiac surgery and 76 of them had neurological complications. Postoperative neurological complications lead to a three-fold longer hospital stay, as well as dependence on mechanical supports and functional disabilities that make it difficult to return to hospital. Previous social status. ${ }^{13}$

In order to help decrease these indices Rocha et al. ${ }^{14}$ conducted a literature review that reinforces the data already discussed and implies that early mobilization supervised by the nursing staff and physiotherapy professionals could be the effective therapy for the prevention of complications after cardiac surgery.

In 2011, a cohort evaluated patients who underwent cardiac surgery and found that $3.3 \%$ of patients developed acute postoperative kidney injury, $2.4 \%$ developed surgical wound infections and 4,3 developed lung infections. ${ }^{15} \mathrm{~A}$ similar study was conducted in Canada and found that urgent surgeries, together with age over 80 years and previous surgeries are factors that influence mortality due to cardiac surgery. ${ }^{16,17,18}$ Still Regarding mortality, the study by Rankin et al. ${ }^{19}$ found that this variable is closely linked with age, gender, comorbidities and type of surgery.
To better appreciate the variable age, studies have been developed with specific age ranges in order to verify the clinical characteristics. A study compared elderly people aged 70 years or older and young adults who underwent myocardial revascularization in this study found that both mortality and incidence of complications were higher in the older group. ${ }^{20}$

Despite the relevance of the study, it has some limitations such as the difficulty of access to the study population due to its critical clinical picture and the difficulty of calculating the sample due to the unpredictable hospital demand.

\section{Conclusion}

Thus, the most frequent complications in the immediate postoperative period of patients undergoing cardiac surgery are pulmonary, cardiac and neurological. Infectious complications appear in small numbers allowing us to infer that infection control measures are being implemented effectively. These data are in agreement with the publications already recorded in the literature and this shows that this research was developed with relevant elective criteria.

Pulmonary complications are firstly found in both research and literature, and this finding may be justified by the need for intubation for at least 48 hours postoperatively. In this sense, it is seen that in the postoperative period, greater attention is required regarding the respiratory system.

\section{Acknowledgements}

None.

\section{Conflicts of interest}

The authors declare no conflicts of interest.

\section{References}

1. https://www.paho.org/bra/index.php?option=com content\&view=articl e\&id=5253:doencas-cardiovasculares $\&$ Itemid=1096.

2. Cani KC, Araujo CLP, Karloh MA, et al. Clinical characteristics of patients undergoing myocardial revascularization surgery. Assobrafir Ciência Dezembro. 2015;6(3):43-54.

3. Dordetto PR, Pinto GC, Rosa TCSCPatients undergoing cardiac surgery: sociodemographic characterization, clinical-epidemiological profile and complications. Rev Fac Ciênc Méd Sorocaba. 2016;18(3):144-149.

4. Baranowska K, Juszczyk G, Dmitruk I, et al. Risk factors of neurological complications in cardiac surgery. Kardio Pol. 2012; 70(8):811-818.

5. Beccaria LM, Cesarino CB, Werneck AL, et al. Postoperative complications in patients undergoing cardiac surgery in a teaching hospital.. Arq Ciênc Saúde. 2015;22(3):37-41.

6. Cordeiro ALL, Amorim NM, Andrade PH, et al. Physiological changes in walking and length of stay in the postoperative period of cardiac surgery. Int J of Cardiovasc Sci. 2015;28(5):480-486.

7. Maitra S, Baidya DK, Bhattacharjee S, Anirban S. Perioperative gabapentin and pregabalin in cardiac surgery: a systematic review and meta-analysis. Rev Bras de Anestesiol. 2017;67(3):294-304.

8. Franco SS, Malbouisson LMS, Grinberg M, et al. A propose of pulmonar dysfunction stratification after valve surgery by physiotherapeutic assistance level. Rev Bras J Cardiovasc Surg. 2015;30(2):188-197.

9. Oliveira JMA, Silva AMF, Cardoso SB, et al. Postoperative complications of cardiovascular surgery with cardiopulmonary bypass. Rev interd interdisc interthesis. 2015;8(1):09-15. 
10. Soares, GMT, Ferreira DCS, Gonçalves MPC, et al. Prevalence of major postoperative complications in cardiac surgery. Rev Bras Cardiol. 2011;24(3):139-146.

11. Calles ACDN, Lira JLF, Granja KSB, et al. Pulmonary complications in patients undergoing coronary artery bypass grafting at a hospital in Maceio, Brazil. Rev Fisioter Mov. 2016;29(4):661-667.

12. Carrascal Y, Guerrero AL, Maroto LC, et.al. Neurological complications after cardiopulmonary bypass: an update. Eur Neurol. 1999;41:128-134.

13. Dessotte CAM, Figueiredo ML, Rodrigues HF, et al. Classification of patients according to the risk of complications and mortality after elective cardiac surgery. Rev Eletr Enf. 2016:18.

14. Rocha RSB, Gomes TCO, Pinto JM, et al. Cardiac surgery and complications: a brief review of the effects of early mobilization on critically ill patients. Revista CPAQV Journal. 2017;9(2):1--8.

15. Haneya A, Diez C, Kolat P, Schwendi MVS, et al. Re-exploration for bleeding or tamponade after cardiac surgery: impact of timing and indication on outcome. Thorac Cardiovasc Surg. 2015;63(1):51-57.
16. Launcelott S, BComm BA, Ouzounian M, et al. Predicting in-hospital mortality after redo cardiac operations: development of a preoperative scorecard. Ann Thorac Surg. 2012;94(3):778-784.

17. Gelape CL. Surgical surgery wound infection following heart. Arq Bras Cardiol. 2007;89(1):e3-e9.

18. Nearman H, Klick JC, Eisenberg P, Pesa N. Perioperative complications of cardiac surgery and postoperative care. Crit Care Clin. 2014;30:527555

19. Rankin JS, Hammill BG, Ferguson TB, et al. Determinants of operative mortality in valvular heart surgery. J Thorac Cardiovasc Surg. 2006;131(3):547-557.

20. Chye-Yew NG, Ramili MF, Awang Y. Coronary bypass surgery in patients aged 70 years and over: mortality, morbidity, length of stay and hospital cost. Asian Cardiovasc Thorac Ann. 2004;12(3):218-223. 